movements, are found among the slower more inefficient readers. It appears that this irregularity is sometimes related to ocular defect, and can be improved by the use of correcting lenses. But it can also be improved by direct re-education in reading habits. The reader practises reading material the words of which are exposed successively in regularly spaced groups by means of the Metron-O-Scope, a piece of apparatus designed and constructed by the author. It is claimed that eye movements become more regular, the perceptual span is increased, and hence the rate of reading improved. Whether in fact the actual comprehension of the reading material is improved seems more doubtful. It is very possible that reading difficulties are in fact due to difficulty in actual comprehension of the words; thus they are not caused by irregularity of eye movement, but are responsible for producing it. Nor should complete regularity of eye movement always be taken as a sign that adequate comprehension is taking place. It is possible for the eyes to move backwards and forwards regularly and mechanically across the printed page without the reader comprehending what he is reading; whereas rapid skimming and comprehension of the material may be accompanied by eye movements of extreme irregularity.

Thus though the author's treatment of the subject is most interesting and suggestive from the ophthalmological point of view, the psychological approach to the subject should not be forgotten.

\title{
CORRESPONDENCE
}

\section{THE TEACHING OF ORTHOPTICS}

\section{To the Editors of THE BRITISH JOURNAL OF OPHThalmology.}

DEAR SIRS,-In reference to a recent letter appearing in this Journal, the Orthoptic Board decided at their last meeting that students must, before commencing study, have passed the School Certificate, the Senior Certificate of the College of Preceptors, or have matriculated at a recognised University within the British Empire.

Yours very truly,

C. L. Gimblett.

$\operatorname{May} 31,1937$. 